\title{
O Processo de Industrialização do Setor Pesqueiro e a Desestruturação da Pesca Artesanal no Brasil a partir do Código de Pesca de 1967
}

\author{
Olga Maria Boschi Aguiar de Oliveira ${ }^{1}$ \\ Vera Lúcia da Silva ${ }^{2}$
}

Resumo: O presente artigo pretende evidenciar a contradição entre o conceito jurídico-legal de pesca artesanal no Brasil e a prática social dessa atividade produtiva. A partir dessa contradição, pretende-se verificar seus efeitos sobre a pesca artesanal. A questão é que a ideologia do industrialismo persiste nas políticas estatais brasileiras, sem qualquer atenção a formas de comércio e de desenvolvimento social afetados pela industrialização forçada. Tal remonta aos intuitos industrialistas característicos do período militarista brasileiro, após 1964 . Nesse sentido, a contradição nas normas do setor pesqueiro conduz à identidade de intuitos e de políticas econômicas desenvolvimentistas, entre o Estado ditatorial e o Estado Democrático contemporâneo, segundo o arranjo institucional atual brasileiro

Palavras-chave: Pesca artesanal. Industrialismo. Estado Democrático.

\begin{abstract}
This paper aims to analyze the contradiction between the legal concept of artisanal fishery in Brazil and the social practice of this economic activity. Starting from this contradiction, it verifies its effects on artisanal fishery. The point is that the ideology of industrialism stills persists in Brazilian public policies, without any attention to the forms of commerce and social development affected by the forced industrialization. This goes back to the industry-based designs characteristic of the Brazilian military period after 1964. Therefore, the contradiction present in the fishery legislation conducts to the identity of designs and economic policies of developmentalism, between the dictatorial state and the democratic state, according to current Brazilian institutional arrangement.
\end{abstract}

Key words: Artisanal fishery. industrialism. Democratic State.

1 Doutora em Direito Social pela Universidad Nacional Autonoma de Mexico (UNAM). Bacharel em Ciências Jurídicas e Sociais pela Pontifícia Universidade Católica do Rio Grande do Sul (PUC-RS). Professora Associada da Universidade Federal de Santa Catarina (UFSC).E-mail: olga@ccj.ufsc.br.

2 Doutoranda na área de Direito, Estado e Sociedade pela Universidade Federal de Santa Catarina (UFSC). Mestre em Filosofia e Teoria do Direito e Graduada em Direito pela UFSC.E-mail: veralms@hotmail.com.

Recebido em: 05/10/2011.

Revisado em: 03/05/2011.

Aprovado em: 25/09/2011. 
O Processo de Industrialização do Setor Pesqueiro e a Desestruturação da Pesca Artesanal no Brasil a partir do Código de Pesca de 1967

\section{Introdução}

A atividade produtiva pesqueira foi regulamentada no Brasil, nas últimas cinco décadas, pelo Decreto-Lei n. 221/1967 (Código de Pesca) e pela Lei de Pesca n. 11.959/2009. A regulação jurídica do setor pesqueiro no Brasil promoveu e continua estimulando a sua industrialização. A partir dessa hipótese de trabalho, pretende-se verificar as consequências das políticas públicas industrialistas do setor pesqueiro sobre a pesca artesanal.

Desde o conceito juridicamente adotado de pesca artesanal na legislação brasileira, até as políticas estatais de estímulo à atividade, acarretam a dissolução do modo de produção artesanal. Essa é a abordagem da primeira e da última parte desse trabalho.

Uma breve análise das práticas sociais e econômicas características da pesca artesanal, elaborada ao logo do texto, permite resgatar condições da pesca artesanal ignoradas pela legislação pesqueira no Brasil. E tais características ignoradas são o que diferencia a pesca artesanal da industrial.

A abordagem da pesca artesanal pelo Estado brasileiro demonstra a continuidade nos intuitos de industrialização. Nesse sentido, o Estado, sob a égide de governos ditatoriais ou democráticos, continua, além de intervindo nos setores produtivos, estimulando um modo de produção e de vida específico e urbano. Ocorre o consequente desaparecimento de um modo de vida tradicional, fundado em bases produtivas comunitárias.

Foram utilizados para a construção e o reforço da presente análise, além de material bibliográfico, dados oficiais de duas instituições governamentais - do recém-criado Ministério da Pesca (2009) e da antiga e extinta (em 1982) Superintendência do Desenvolvimento da Pesca (SUDEPE). Pretende-se analisar o fenômeno da dissolução da pesca artesanal e atestar que, por maiores que sejam as intenções de resgate dessa prática, a intervenção desenvolvimentista estatal somente consolida a indústria pesqueira. 
Olga Maria Boschi Aguiar de Oliveira e Vera Lúcia da Silva

\section{Conceito Jurídico-Legal Pesca Artesanal no Brasil}

A pesca artesanal por muito tempo permaneceu sem definição jurídica no Brasil. Foi objeto de regulamentação somente no ano de $2003^{3}$. Antes disso, era prática sem regulamentação legal. Os pescadores, na condição artesanal, eram reconhecidos como profissionais, mas não detinham, até 2003, benefícios especiais previdenciários ou trabalhistas.

Atualmente, a definição jurídica válida é datada de 2009. Ainda não é um conceito preciso ${ }^{4}$. Isso porque a pesca artesanal é uma atividade desenvolvida em todo o litoral brasileiro, na sua extensão aproximada de 8.000 quilômetros. Além dos limites costeiros, a pesca dita artesanal também ocorre em águas lacustres e fluviais. Pela variedade de formas de execução da pesca artesanal, o esforço de uma definição geral e detalhada parece ser tão complexo quanto inviável.

No mais, a única definição jurídica que se tem desde 2009 da pesca artesanal é bastante dúbia. Isso porque o que se compreende por pesca artesanal é a atividade: 1) realizada em regime de economia familiar; e 2) desenvolvida por meio de embarcações de pequeno porte. Inicialmente, cumpre lembrar que nem toda a forma de pesca artesanal utiliza-se

3 Previsão pela Lei n. 10.779/2003 - Lei que regulamenta o seguro desemprego ao pescador artesanal durante o período do defeso. Art. $1^{\circ} \mathrm{O}$ pescador profissional que exerça sua atividade de forma artesanal, individualmente ou em regime de economia familiar, ainda que com o auxílio eventual de parceiros, fará jus ao benefício de segurodesemprego, no valor de um salário-mínimo mensal, durante o período de defeso de atividade pesqueira para a preservação da espécie.

4 Definição prevista na Lei n. 11.959, de 29 de junho de 2009, que dispõe sobre a Política Nacional de Desenvolvimento Sustentável da Aquicultura e da Pesca, regula as atividades pesqueiras, em substituição ao Código de Pesca de 1967. A pesca artesanal é definida atualmente como modalidade de pesca comercial, realizada diretamente pelo pescador, autonomamente ou com auxílio do grupo familiar, em embarcações de pequeno porte. Assim, a pesca artesanal passou a ser definida somente em 2009, através da referenciada lei, nos seguintes termos: Art. $8^{\circ}$. Pesca, para os efeitos desta Lei, classifica-se como: I - comercial: a) artesanal: quando praticada diretamente por pescador profissional, de forma autônoma ou em regime de economia familiar, com meios de produção próprios ou mediante contrato de parceria, desembarcado, podendo utilizar embarcações de pequeno porte. Disponível em: <http://www.planalto.gov.br/ccivil_03/_Ato2007-2010/2009/Lei/ L11959.html . Acesso em: 7 jul. 2011. 
O Processo de Industrialização do Setor Pesqueiro e a Desestruturação da Pesca Artesanal no Brasil a partir do Código de Pesca de 1967

de embarcações. E, mesmo que a base essencial da pesca fosse o tipo de embarcação, ainda assim há que se considerar a inexistência de um consenso a respeito dos limites entre embarcações de pequeno e médio porte. A lei não define quais seriam as embarcações de pequeno porte, restando dúvida quanto à sua caracterização. Além disso, o regime de economia familiar não é explicado pela própria lei. Segundo a lei previdenciária, o regime de economia familiar dispensa mão de obra assalariada. Entretanto, não há clareza quanto ao seu alcance, e como se caracteriza em um modo de produção comunitário.

Talvez a dubiedade da definição técnica e jurídica sobre o que seja a pesca artesanal deva-se à sua inexpressividade em termos produtivos. Esse argumento poderia ser refinado, constatando-se os poucos estudos realizados no Brasil a respeito da prática da pesca artesanal. Entretanto, tal conclusão é completamente falsa. E seu erro verifica-se em dois níveis, ao menos.

O primeiro deles é um equívoco quanto à relevância econômica da pesca artesanal. Além de seu produto ser voltado para a alimentação imediata da família do pescador, serve também como fonte importante de meios econômicos para toda a comunidade envolvida. Ao lado da importância local de sustento das comunidades da atividade pesqueira artesanal, dados oficiais da Empresa de Pesquisa Agropecuária e Extensão Rural de Santa Catarina (EPAGRI) registram que, em 2004, o número de pescadores artesanais era de aproximadamente 25.000 (vinte e cinco mil) pessoas somente no Estado de Santa Catarina. A atividade desse grupo representava a produção de 30\% (trinta por cento) da produção de pescado no mesmo Estado (SEVERO, 2008). Dados nacionais apontam para 600 mil famílias envolvidas na produção pesqueira artesanal, dentre comunidades ribeirinhas e litorâneas.

Outro nível de falsidade da conclusão sobre a inexpressividade da pesca artesanal verifica-se pela importância da continuidade de uma atividade tradicional, característica de certas comunidades que se identificam como pesqueiras. É a pesca artesanal, além de fonte de condições objetivas de subsistência, uma maneira de manutenção de vínculos humanos. É através do conhecimento do mar, passado geração a geração, que gru- 
pos familiares ganham identidade e afinidade - os pescadores. Portanto, a pesca artesanal oferece para as comunidades pesqueiras brasileiras mais que condições objetivas de vida. Dada pela interação do homem com o meio ambiente natural, surge também uma subjetividade, variável regionalmente. (PASQUOTTO, 2005)

Apesar da importância econômico-social da atividade, a pesca artesanal não foi regulamentada juridicamente até o ano de 2003. A regulamentação jurídica de todo o setor pesqueiro válida até 2003 foi o Código de Pesca, de 1967. Tal Código trazia simplesmente definições genéricas quanto à figura do pescador. A pesca artesanal não era definida - simplesmente foi definida como ramo da pesca, realizada por pescador profissional.

O Código de Pesca de $1967^{5}$ definia a atividade de pesca conforme o agente que a realizava. Havia três grandes grupos de agentes: o pescador profissional, o pescador amador e o cientista. Ao amador era autorizada a utilização unicamente de embarcações para a prática de pescaria recreativa $^{6}$, sem qualquer finalidade comercial. Aos cientistas ${ }^{7}$, igualmente

5 Decreto-Lei n. 221, de 28 de fevereiro de 1967. Dispõe sobre a proteção e estímulos à pesca e dá outras providências. Revogou o Decreto-Lei n. 794, de 19 de outubro de 1938, que até então regulava a pesca no Brasil. Cabe salientar que a competência para regulamentar a atividade pesqueira no Brasil era, e permanece ainda pela Constituição da República Federativa do Brasil vigente nos dias atuais (de 5 de outuro de 1988), da União Federal. (Art. 22. Compete privativamente à União legislar sobre: I - direito civil, comercial, penal, processual, eleitoral, agrário, marítimo, aeronáutico, espacial e do trabalho). (grifo nosso)

6 O pescador amador necessitava, como ainda necessita, de registro de pesca, fornecido pelo Ministério da Marinha, através das sessões da Capitania dos Portos. Para a concessão do referido registro é necessário que o pescador realize provas teóricas de conhecimentos básicos em navegação. Com a aprovação nas provas, consegue-se a habilitação para as seguintes modalidades: Capitão-Amador - apto para conduzir embarcações entre portos nacionais e estrangeiros, sem limite de afastamento da costa. Mestre-Amador - apto para conduzir embarcações entre portos nacionais e estrangeiros nos limites da navegação costeira. Arrais-Amador - apto para conduzir embarcações nos limites da navegação interior. Motonauta - apto para conduzir JET-SKI nos limites da navegação interior. Veleiro - apto para conduzir embarcações a vela sem propulsão a motor, nos limites da navegação interior. Fonte: sítio da Capitania dos Portos do Rio de Janeiro. Disponível em: $<$ https://www.mar.mil.br/cprj/habama.html\#>. Acesso em: 6 jul. 2011.

7 Também é o Ministério da Marinha, por meio das Capitanias dos Portos, que detém a atribuição para conceder registro de embarcações e de pesquisadores para a realização 
O Processo de Industrialização do Setor Pesqueiro e a Desestruturação da Pesca Artesanal no Brasil a partir do Código de Pesca de 1967

a pesca não comercial era autorizada. A única categoria autorizada legalmente à pesca com intuito comercial foi o pescador profissional.

Entre os pescadores profissionais, o Código de Pesca de 1967 não apresentava qualquer categorização. Apresentava unicamente a definição "pescador profissional", como sendo "aquele que faz da pesca sua profissão e seu meio principal de vida"». Isso porque a distinção entre as categorias de pescadores não constituía o principal foco do Código de Pesca. Essa afirmação é perceptível pelo próprio teor dos demais artigos do Código, cuja preocupação era a definição da atividade pesqueira para a concessão de benefícios às empresas pesqueiras, tal como isenção de im$\operatorname{postos}^{9}$.

de pesca com intuito de pesquisa científica. Aos pescadores nessa categoria, é exigido o registro da embarcação unicamente com finalidade de pesquisa e que seja vinculada a instituições brasileiras de pesquisa que detenham por Lei a atribuição de coletar material biológico para fins científicos (artigo 32, Código de Pesca de 1967).

8 Decreto-Lei n. 221, de 28 de fevereiro de 1967. Artigo 26 - Pescador Profissional é aquele que, matriculado na repartição competente segundo as leis e regulamentos em vigor, faz da pesca a sua profissão ou meio principal de vida. Segundo o artigo 28, no seu parágrafo primeiro, a matrícula será emitida pela Capitania dos Portos e Ministério da Marinha.

9 Cumpre relembrar que o Código de Pesca foi publicado na época do Regime Militar Brasileiro, instaurado em 1964, quando foi deposto o presidente João Goulart. Seguia-se, à época, a ideologia de estímulo ao desenvolvimento nacional (ou perseguia-se a ideia de Milagre Econômico Brasileiro), cuja meta era promover desenvolvimento de "cinquenta anos em cinco". O próprio Código de Pesca de 1967 tem por objetivo o estímulo ao desenvolvimento nacional, através da industrialização do setor pesqueiro. Com vistas ao referido desenvolvimento, a preocupação com as condições de vida e trabalho, ou mesmo as preocupações sociais em relação aos trabalhadores da pesca eram tímidas (senão nulas). Por essa razão, o Código de Pesca de 1967 não se dedica à definição de pescador, e pouco dispõe sobre o funcionamento das entidades representativas dos pescadores (Sindicatos). A preocupação maior era justamente em oferecer estímulo à industrialização do setor produtivo pesqueiro. Tanto assim é que, a partir do Código de Pesca, pessoas jurídicas nacionais tiveram isenção sobre imposto de importação sobre produtos industrializados (embarcações, maquinários e petrechos de pesca) até 1982 (artigo 73), bem como isenção de Imposto de Renda incidente sobre os resultados financeiros obtidos até o ano de 1989 (artigo 80). Vê-se, portanto, a grande preocupação com o estímulo ao desenvolvimento do setor pesqueiro, e poucas preocupações sociais com o pescador. 
Ao pescador profissional dedicado à pesca industrial, alguns direitos já eram garantidos em 1967, como receber remuneração durante o período de vedação legal à pesca de determinadas espécies (conhecido como defeso ${ }^{10}$, além da contagem do tempo para a aposentadoria obedecer a regras especiais ${ }^{11}$. Tais regras para aposentadoria especial são previstas não no Código de Pesca, mas no artigo 31 da Lei n. 3.807, de 1960, abrangendo todos os trabalhadores em condições penosas e/ou insalubres $^{12}$. Mas esses direitos não eram estendidos aos pescadores autônomos artesanais.

Somente em 2003, por meio do Registro Geral de Pesca, é possível ao pescador comercial, tanto industrial como artesanal, comprovar atividade pesqueira e usufruir dos benefícios assegurados para a sofrida categoria profissional - dentre eles a aposentadoria em menor tempo de con-

10 Defeso: período legal, determinado pelo órgão de tutela ambiental (Instituto Brasileiro do Meio Ambiente - IBAMA), em que é proibida a pesca e captura de certas espécies de pescados. Algumas espécies de animais aquáticos precisam de proteção em certas épocas do ano, quando ocorre a sua reprodução. A pesca realizada no momento de reprodução de espécies marinhas, como o camarão, acarreta a diminuição sensível dos cardumes. Para evitar o comprometimento e a extinção das espécies, há regulamentação governamental na proibição da pesca de determinadas espécies por algum período anual (como o caso do camarão e da anchova). Algumas vezes ocorrem vedações momentâneas e extraordinárias, quando da diminuição drástica de determinadas espécies. Esse período de proibição da pesca é chamado "defeso", e pode variar de duração conforme a espécie pesqueira e o grau de comprometimento da espécie.

11 Para aposentadoria, em virtude das condições de trabalho do pescador, é necessário contar o período de 20 anos de exercício profissional, com respectivo recolhimento de contribuição previdenciária. Entretanto, cada ano profissional completo corresponde a 250 (duzentos e cinquenta) dias e não 365 (trezentos e sessenta e cinco) dias como o calendário convencional. Por conta disso é possível ao pescador aposentar com menor tempo de contribuição à Previdência Social se comparado aos trabalhadores não embarcados.

12 “Artigo 31. A aposentadoria especial será concedida ao segurado que, contando no mínimo 50 (cinquenta) anos de idade e 15 (quinze) anos de contribuições tenha trabalhado durante 15 (quinze), 20 (vinte) ou 25 (vinte e cinco) anos pelo menos, conforme a atividade profissional, em serviços, que, para êsse efeito, forem considerados penosos, insalubres ou perigosos, por Decreto do Poder Executivo." (sic). 
O Processo de Industrialização do Setor Pesqueiro e a Desestruturação da Pesca Artesanal no Brasil a partir do Código de Pesca de 1967

tribuição ${ }^{13}$ para a Previdência Social, seguro desemprego ${ }^{14}$ nos períodos de defeso ${ }^{15}$ e benefício de auxílio doença e por acidente de trabalho ${ }^{16}$.

Assim, houve concomitantemente dois regimes jurídicos para os pescadores - um destinado aos pescadores profissionais da indústria da pesca e outro para os pescadores artesanais, que só passaram a ser igualmente considerados aos pescadores industriais, para fins previdenciários, em 2003. Tal discrepância releva o descaso em relação ao modo de produção estruturado na pesca artesanal.

13 A Previdência Social brasileira estabelece, pela Lei n. 8.213, de 1991, a necessidade de combinar-se o critério etário com o tempo de contribuição à Previdência Social, para o segurado-trabalhador fazer jus à aposentadoria integral (pelo Regime Geral da Previdência Social). É necessário, para aposentar-se com proventos integrais relativos ao valor de contribuição, até o teto (em torno de três mil e quinhentos reais atualmente), deter homens 35 anos de contribuição e mulheres 30 anos. O critério etário é concomitante ao critério contributivo. Mas, no caso dos pescadores há uma redução da exigência, em virtude das condições inerentes à pesca. Para aposentar, o pescador deve contar com o mínimo de sessenta anos de idade, se homem, e cinquenta e cinco, se mulher. Às contribuições dos que exercem atividade laboral perigosa ou insalubre, para a aposentadoria o poder público deve combinar a idade com o tempo de 180 meses (15 anos) de contribuição.

${ }^{14}$ O Seguro-Desemprego é um benefício integrante da seguridade social, garantido pelo art. $7^{\circ}$ dos Direitos Sociais da Constituição Federal, e tem por finalidade promover a assistência financeira temporária ao trabalhador desempregado, em virtude da dispensa sem justa causa. Consiste no pagamento de 3 (três) a 5(cinco) parcelas, de valores variáveis até o teto aproximado de $\mathrm{R} \$ 800,00$ (oitocentos reais). Fonte: Ministério do Trabalho e Emprego. Disponível em: <http://www.mte.gov.br/seg_desemp/default.asp $>$. Acesso em: 13 jul. 2011.

${ }^{15}$ Importante salientar que, durante o período de defeso, cabe ao pescador profissional receber remuneração. Quanto ao pescador artesanal, a Lei n. 10.779, de 25 de novembro de 2003, garante ao pescador receber tantas parcelas quantos forem os meses de duração do defeso, conforme portaria fixada pelo IBAMA. O valor de cada parcela é de um salário mínimo. Fonte: sítio do Ministério do Trabalho e Emprego (MTE). Disponível em: <http://www.mte.gov.br/seg_desemp/modalidades_artesanal.asp $>$. Acesso em: 6 jul. 2011.

16 É prevista a "cobertura dos eventos de doença, invalidez, morte, incluídos os resultantes de acidentes do trabalho, velhice e reclusão" (grifo nosso) pela Previdência Social. Tal é o disposto no artigo 201, inciso I da Constituição da República Federativa do Brasil, de 5 de outubro de 1988. A Lei n. 8213, de 1991 definiu, no seu artigo 19, o que é acidente de trabalho. 
Recentemente, a Lei n. 11.959/2009 regulamentou um conceito operacional e jurídico de pesca artesanal, objetivando o reconhecimento legal dessa atividade. A pesca artesanal foi inserida na atual lei de pesca (2009) como modalidade de pesca comercial, “[...] praticada por pescador profissional, de forma autônoma ou em regime de economia familiar"17.

O pescador profissional é a pessoa física, brasileira ou estrangeira, residente no Brasil, que conta com licenciamento de órgão público para a execução da atividade pesqueira. Portanto, para a realização da pesca artesanal é necessário registro do pescador junto ao órgão competente - que no caso são as Colônias de Pescadores. Recentemente (desde 2003), todos os registros de pesca passaram a ser centralizados pela Secretaria Especial da Aquicultura e Pesca (SEAP). De toda a forma, é imprescindível o atestado fornecido pelas Colônias de Pescadores comprovando a realização de atividade pesqueira para a concessão do referido Registro Geral de Pesca (embora também seja possível substituir a declaração referida por um atestado assinado por dois pescadores que já detenham Registro Geral de Pesca $)^{18}$. Mesmo assim, está guardada a importância da declaração e da filiação do pescador à Colônia de Pescadores.

As referidas Colônias são organizações de pescadores que surgiram desde 1808, quando foi criada a primeira Colônia de Pescadores na região nordeste do Brasil ${ }^{19}$. Eram entidades que regulavam o exercício da pesca em suas circunscrições. A regulação era exercida através do registro de pescadores e de embarcações. Surgiam da livre iniciativa dos pescadores, que se reuniam em Colônias para assegurar coletivamente os interesses da classe trabalhadora da pesca. Ocorre que, à época do Código de Pesca de 1967, as Colônias foram todas elas reorganizadas e, algumas inclusive instaladas pelo Poder Executivo da União ${ }^{20}$. Tal medida representou forte

17 Conforme o que se depreende do artigo 19 da Lei n. 11.959, de 2009.

18 Informação da própria Secretaria Especial da Pesca e Aquicultura, no sítio <www. mpa.gov.br>.

19 Surgiu no Sul do Estado da Bahia. Corresponde à Primeira Zona Pesqueira registrada do país. Por isso, é conhecida como Colônia Z-1, localidade de Rio Vermelho no município de Santa Cruz Cabrália, a 22 quilômetros de Porto Seguro. Fonte Jornal do Sol, Porto Seguro. Disponível em: <http://www.jornaldosol.com.br/?/>. Acesso em: 13 jul. 2011.

20 É o que determinou os artigos 91 e 94 do Código de Pesca de 1967. 
O Processo de Industrialização do Setor Pesqueiro e a Desestruturação da Pesca Artesanal no Brasil a partir do Código de Pesca de 1967

intervenção estatal sobre o órgão de classe da categoria dos pescadores artesanais. Significa, portanto, que o governo brasileiro instalado durante o Regime Militar tomou a frente das organizações de classe dos pescadores. Assim, reivindicações da categoria eram contidas no próprio órgão representativo.

O regime de economia familiar é definido somente pela lei previdenciária. Esse regime se caracteriza pelo desenvolvimento de atividade de subsistência, autonomamente desenvolvida ou pelo grupo familiar, sem intervenção de mão de obra assalariada ${ }^{21}$. É atividade realizada por grupos familiares em torno da atividade produtiva, ou, no máximo, contratos de parceria pesqueira. Nesses contratos, não há o estabelecimento de salários, mas de participação nos lucros da produção. Por esse sistema, cada pescador faz jus a uma parte da produção, assim como o proprietário da embarcação. (DIEGUES, 1983)

A definição jurídica de pesca artesanal é importante em dois níveis. No primeiro, a regulamentação da atividade possibilita o reconhecimento profissional dos trabalhadores. E sendo assim, o pescador passa a resguardar para si todos os direitos advindos das atividades laborais, especialmente em relação aos benefícios previdenciários. E, por último, mas não menos importante, a regulamentação serve como maneira de afirmar políticas públicas de estímulo a atividades comunitárias e não-industriais, atividades negligenciadas e, inclusive, suprimidas pelos regimes autoritários brasileiros.

Equiparou-se à atividade pesqueira, pela referida lei, “[...] os trabalhos de confecção e de reparos de artes e petrechos de pesca, os reparos realizados em embarcações de pequeno porte e o processamento do produto da pesca artesanal ${ }^{22}$. Por essa previsão, a definição jurídica da pesca artesanal buscou considerar como pescador tanto o sujeito embarca-

21 Conforme o artigo 11, VII, da Lei n. 8.213/91, § 1º que dispõe, in verbis: "Entende-se como regime de economia familiar a atividade em que o trabalho dos membros da família é indispensável à própria subsistência e é exercido em condições de mútua dependência e colaboração, sem a utilização de empregados."

22 Recorte do texto do parágrafo único do artigo $4^{\circ}$, Lei n. 11.959, de 29 de junho de 2009. 
do, como o produtor de petrechos de pesca (equipamentos manufaturados como redes e espinhéis ${ }^{23}$, por exemplo).

Entretanto, o próprio texto legal determina que tal equiparação somente é considerada para os "efeitos" da própria lei. Então, o alcance da equiparação dessas atividades à pesca artesanal não atinge a legislação previdenciária e trabalhista. O limite da lei é a concessão de crédito para estímulo da atividade pesqueira artesanal. Ou seja, a equiparação só ocorre para conceder financiamentos especiais.

Ora, a grande questão é que os trabalhos de produção de petrechos e processamento de pescado somente serão considerados pesca artesanal para as definições da própria lei - como para a concessão de crédito rural e financiamentos (benefícios que anteriormente não eram estendidos à pesca artesanal). Quanto à garantia e extensão dos direitos sociais dos pescadores artesanais aos "pescadores equiparados", a ausência de tutela jurídica persiste.

Em 2003, passou-se a deter um conceito de pesca artesanal com validade jurídica para a finalidade de seguro-desemprego. Sua aplicação imediata era para garantir aos pescadores que realizassem suas atividades em regime de economia familiar ou em parceria com outros o benefício de seguro desemprego durante o defeso. Assim, o enfoque da legislação de 2003 servia à garantia de um dos direitos previdenciários do trabalhador ao pescador artesanal. Já a legislação posterior, embora não tenha revogado a de 2003, nada garante em termos de direitos sociais. O objetivo da lei de 2009 é estimular a prática pesqueira artesanal por via de empréstimos bancários a taxas de juros baixas. Não há qualquer concessão de benefícios por parte da lei de 2009 às comunidades que já foram dizimadas pelas políticas estatais antecedentes para a industrialização do setor pesqueiro.

A prática da pesca artesanal seria estimulada por via da concessão de crédito rural, segundo a lei de pesca de 2009. Esse crédito consiste na

23 Redes de pesca são aparelhos para pescar flexíveis, geralmente de fibras relativamente delgadas e com malhas de tamanho menor que a menor dimensão dos peixes ou mariscos que se pretendem capturar com elas. Já os espinhéis são estruturas dotadas de uma linha central firme, de onde partem linhas secundárias, dotadas de anzóis nas pontas. 
O Processo de Industrialização do Setor Pesqueiro e a Desestruturação da Pesca Artesanal no Brasil a partir do Código de Pesca de 1967

oferta de financiamento, por meio de projetos registrados junto ao Ministério do Desenvolvimento Agrário (MDA) do governo federal. A inscrição de projetos deve estar dentro das linhas oferecidas pelo programa de crédito rural. Nas várias linhas de financiamento, poderão ser liberados até $\mathrm{R} \$ 120.000,00$ (cento e vinte mil reais) pelo governo federal, a serem pagos no período de cinco anos, com juros muito abaixo dos valores de mercado. Tem por objetivo famílias que tenham renda bruta familiar até $\mathrm{R} \$ 6.000,00$ (seis mil reais) mensais, sendo que 70\% (setenta por cento) dos rendimentos provenham da agricultura ou da pesca familiar. ${ }^{24}$

Em suma, tem-se que a pesca artesanal no Brasil foi provisoriamente prevista em lei no ano de 2003 (e não antes desse ano). Antes disso, qualquer política para o setor pesqueiro voltava-se ao estímulo do desenvolvimento da pesca industrial. A definição de pesca artesanal em 2003 tinha por objetivo prever o benefício previdenciário de seguro desemprego aos pescadores na época do defeso. Em 2009, a atividade pesqueira artesanal foi definida por nova lei, que estabeleceu a pesca artesanal como prática de economia familiar, promovida por meio de pequenas embarcações. A essa modalidade pesqueira, foram oferecidos estímulos creditícios. Via crédito rural, o pescador artesanal pode receber financiamento de suas atividades a juros muito abaixo dos praticados no mercado. Foi somente essa a previsão da nova lei de pesca sobre pesca artesanal, com objetivo de estimular as comunidades pesqueiras a se voltarem para a prática dessa modalidade. É de se questionar pelas formas de realização da pesca artesanal no Brasil, a fim de se verificar a adequação da oferta de crédito ao propósito de estímulo ao pequeno produtor artesanal. Em outras palavras, investigar se, a partir das condições da pesca artesanal no Brasil, a concessão de crédito rural é relevante e suficiente para estimular sua prática.

24 Dados Ministério do Desenvolvimento Agrário, disponíveis em: <http://portal.mda. gov.br/portal/saf/programas/pronaf/2258903>. Acesso em: 17 jul. 2011. 
Olga Maria Boschi Aguiar de Oliveira e Vera Lúcia da Silva

\section{A Pesca Artesanal e sua Prática no Brasil}

Como a pesca artesanal é determinada pela relação do ser humano com o meio ambiente, há uma grande variabilidade de técnicas para execução da tarefa pesqueira. Em algumas regiões, a pesca é realizada por meio de pequenos botes e canoas, movidos à vela ou por remos. Esse é o caso da pesca da tainha, realizada ainda no litoral de Santa Catarina e do Estado de São Paulo. Também ocorre essa modalidade pesqueira na captura da Lagosta, na localidade de Mataraízes, no Estado de Espírito Santo. Ou ainda na pesca realizada no Rio Amazonas ${ }^{25}$. Em outras regiões, percebe-se o convívio dos pequenos botes com embarcações movidas a motores de pequena potência (de 5 a $10 \mathrm{HP}$ ), comportando até dois pescadores (modalidade desenvolvida nas praias de Florianópolis ${ }^{26}$ e de Bombinhas $^{27}$ ). Há locais em que a pesca artesanal pode envolver embarcações com motores até $18 \mathrm{HP}$, contando com o trabalho de até quatro homens (encontra-se tal modalidade de pescaria na Lagoa dos Patos ${ }^{28}$ ). Nessa última modalidade, o proprietário da embarcação divide a produção e a chefia dos trabalhos com os demais. Ainda há localidades em que a pesca

25 No litoral paulista, ainda se destacam as localidades de Ilhabela, Picinguaba e Ubatuba, no litoral norte, e Iguape-Cananeia no litoral sul. Comunidades que vivem em torno ao Rio Amazonas também realizam destacadamente a pesca artesanal, no intuito de sustento do próprio núcleo comunitário. (DIEGUES, 1983)

26 Capital do Estado de Santa Catarina, situado na região Sul do Brasil. Localiza-se no centro-leste do Estado de Santa Catarina e é banhada pelo Oceano Atlântico. Grande parte de Florianópolis $(97,23 \%)$ está situada na Ilha de Santa Catarina, possuindo cerca de 100 praias, consideradas também as continentais.

27 Bombinhas é um município brasileiro situado no Estado de Santa Catarina. A economia do município é fundada na exploração da atividade turística durante os meses de verão e no inverno sobrevive por meio da pesca (industrial e artesanal). A pesca artesanal ocorre em todas as 12 praias que compõem o município. É o menor município de Santa Catarina, com uma área de $34,5 \mathrm{~km}^{2}$, cuja população é constituída fundamentalmente de descendentes de portugueses e açorianos. (IBGE). <www.ibge.gov.br>. Acesso em: 17 jul. 2010.

28 Lagoa dos Patos é a maior laguna do Brasil e a segunda da América Latina, situa-se no estado brasileiro do Rio Grande do Sul. Tem 265 quilômetros de comprimento e uma superfície de $10.144 \mathrm{~km}^{2}$, estendendo-se paralelamente ao Oceano Atlântico. 
O Processo de Industrialização do Setor Pesqueiro e a Desestruturação da Pesca Artesanal no Brasil a partir do Código de Pesca de 1967

artesanal ocorre em manguezais, sem nem mesmo a estrutura de embarcações (localidades como Itapissuma ${ }^{29}$ ).

É necessário considerar que também é variável o limite marítimo em relação à distância da costa litorânea em que é realizada a pesca artesanal. Alguns trabalhos na área referenciam como limite a "plataforma continental rasa", o que não explica muito em distância marítima. (CHAVES; ROBERT, 2003)

Em qualquer das situações fica descaracterizada qualquer relação de emprego formal, pois nenhum dos envolvidos na atividade pesqueira é assalariado ou comandado por outro. Ocorre, sim, uma série de acordos locais no momento da pescaria, quando se determina quem coordenará a ação pesqueira.

Por meio dessa simples e brevíssima análise, é possível constatar a dificuldade na definição da modalidade pesca artesanal. Sabe-se, entretanto, que é uma atividade profissional de caráter tradicional, em que o conhecimento técnico é desenvolvido pelo contato do pescador com o meio ambiente (SEVERO, 2008). E, mais ainda, tal conhecimento é repassado entre gerações de uma mesma família, pela oralidade ${ }^{30}$. Por isso, há dificuldade de uma definição unívoca da categoria pesca artesanal.

Apesar disso, é comum a toda e qualquer prática de pesca artesanal o desenvolvimento da atividade pesqueira em regime familiar. Além do

${ }^{29}$ É município brasileiro do Estado de Pernambuco. Lá as mulheres fazem coleta de moluscos (de marisco, de ostra, de sururu), de caranguejo e de siri no Canal de Santa Cruz e nos estuários. Geralmente, a coleta é feita a pé e com utilização de técnica manual e de instrumentos como a foice, o estilete e o espeto de madeira. (MELO, 2008)

${ }^{30}$ Trata-se da dificuldade em tornar racionais ações sociais tradicionais. Tais ações escapam ao limite de definição geral e burocrática (WEBER, 2009). Dependem em demasia dos estudos empíricos e da realidade local abordada. Há características próprias em cada lugar de realização da atividade pesqueira artesanal. Alguns trabalhos acadêmicos referenciados no presente trabalho adotam uma perspectiva sistêmica de abordagem, justamente para evitar desconsiderar a variabilidade das comunidades pesqueiras. Essa variabilidade envolve tanto os instrumentos utilizados quanto a organização dos sujeitos envolvidos. Isso porque em cada região pesqueira há o desenvolvimento da pesca em relação ao local e ao pescado coletado. E mais ainda, há localidades e situações em que é comum a combinação de diversos sistemas de pesca. (PASQUOTTO, 2005) 
mais, é comum também a existência de um modo de produção comunitário, envolvendo a população de uma determinada localidade nos processos de captura, beneficiamento e comércio do pescado, fato ignorado pela lei de 2009. Essas duas características resultam na incipiente divisão do trabalho, sem, portanto, uma organização capitalista para a exploração de sobre-trabalho. Além disso, outra característica vinculada ao modo de produção artesanal é sua base produtiva no valor de uso, sem acúmulo de capital ou mesmo de exploração da mais-valia ${ }^{31}$. (DIEGUES, 1983, p. 191-192)

Uma terceira característica comum e incontestável da pesca artesanal, também não considerada pela Lei de 2009, é o aparato material rudimentar no processo de captura e beneficiamento do pescado. Tal fator determina condições de produção bastante limitadas, o que reduz a autonomia das embarcações. Com isso, o cardume pesqueiro alvo da pesca artesanal circunda águas costeiras e rios. Surge daí uma espécie de relação preservacionista, a fim da manutenção desses cardumes próximos à costa. Tal relação implica o respeito aos períodos de reprodução e desova, bem como o tamanho mínimo do pescado, para que se possibilite a renovação das espécies.

Para compreender as características gerais da pesca artesanal é necessário descrever a atividade peculiar das comunidades pesqueiras. Enquanto raras comunidades ainda praticam a pesca artesanal como meio de subsistência (essencialmente no Amazonas), outra grande parte promove a pesca de pequena produção mercantil. É sobre esta o maior número de dados disponíveis, bem como engloba maior parte das comunidades pesqueiras atuais (DIEGUES, 1983). Portanto, será sobre essa modalidade a que se deterá esta pesquisa.

31 Essa anotação é importante e conveniente, a fim de diferenciar o trabalho realizado na pesca artesanal em relação à indústria pesqueira. Isso porque o modo de produção indica as relações sociais e culturais envolvidas nos processos produtivos. A utilização das categorias marxistas serve de aporte à reflexão elaborada, por retratarem a exploração humana no processo de industrialização capitalista. Tal industrialização não acarreta o bem-estar humano: ao contrário, provém da acumulação primitiva de capital e gera a concentração de capital em segundo momento. 
O Processo de Industrialização do Setor Pesqueiro e a Desestruturação da Pesca Artesanal no Brasil a partir do Código de Pesca de 1967

A sistemática dos trabalhos pesqueiros desenvolvidos artesanalmente no Brasil engloba, corriqueiramente, nas regiões litorâneas e ribeirinhas, o manejo de pequenas embarcações pesqueiras. A depender da região, essas embarcações são conduzidas e tripuladas por homens, com vedação explícita à presença de mulheres na tripulação. Com isso, surge uma incipiente divisão social do trabalho, por gênero. Enquanto os homens dedicam-se à captura do pescado, as mulheres ocupam-se dos afazeres domésticos e do beneficiamento do pescado em terra.

Entretanto, algumas localidades empregam o trabalho feminino na captura do recurso pesqueiro. Na localidade conhecida como Baía da Babitonga, costa interior da Ilha de São Francisco do $\mathrm{Sul}^{32}$, as mulheres encontram espaço para trabalhar inclusive na condução dos barcos pesqueiros. Além da condução dos barcos, as mulheres, independentemente da participação de seus maridos, promoviam a colocação e a retirada das redes de pesca. (BORGONHA; BORGONHA, 2008)

Na referida localidade, tal prática pesqueira pelas mulheres foi determinada pela própria condição geográfica da região. A baía, com águas tranquilas, permitiria o acesso das mulheres ao mar, sem grandes riscos. É o que se depreende dos próprios relatos das mulheres pescadoras da região ${ }^{33}$.

Ocorre que, da década de 1980 em diante, tal forma de execução da pesca não vem se reproduzindo. Isso porque houve o desenvolvimento urbano do município de São Francisco do Sul, através da exploração turística. Dessa forma, muitas das mulheres não seguiram a pesca como

32 São Francisco do Sul é a terceira localidade mais antiga do Brasil. Foi descoberta em 1504 por franceses, mais especificamente pela Expedição de Binot Paulmier de Gonneville. Sua população estimada em 2008 era de 39.341 habitantes. Possui uma área de $493 \mathrm{~km}^{2}$. A sede do município está localizada no extremo norte da ilha de São Francisco do Sul, na entrada da Baía Babitonga. Engloba, em sua extensão, pequenas ilhas dentro da própria Baía, além de compreender uma porção territorial no continente. Dados - Instituto Brasileiro de Geografia (IBGE). <www.ibge.gov.br>. Acesso em: 17 jul. 2010.

33 Especialmente refere-se às localidades Ponta da Caieira, na Ilha de São Francisco do Sul, e em duas pequenas Ilhas que compõem o Município - Ilha Grande e Ilhas Claras. 
forma laboral, mas destinaram-se à mão de obra na empresa turística ${ }^{34}$. Mesmo assim ainda são encontradas, embora em número muito menor, mulheres pescadoras. E fundamentalmente, entre as mulheres mais antigas da comunidade é possível encontrar relatos da atividade pesqueira por elas desenvolvida.

Além da atividade de captura do pescado, as mulheres, em maior número, promovem o beneficiamento inicial do pescado nas praias. Quando o barco chega à praia ou aos trapiches, é efetuada a descarga dos peixes. Muitas vezes, são utilizadas estruturas de vime ou bambu, chamadas samburá. Esses recipientes profundos são o meio pelo qual o pescador leva o pescado à praia. Já na praia, as mulheres aguardam a descarga do pescado. Ali, as mulheres realizam a separação das espécies de pescado e a pesagem. Após esse procedimento, as mulheres são incumbidas da limpeza dos peixes, que engloba a retirada das escamas e a esvisceração. No caso da pesca do camarão, as mulheres passam-no para um tanque e iniciam a retirada de sua carapaça.

Então, as mulheres são responsáveis por tornar o pescado livre de suas partes inutilizáveis ao consumo humano. E, dessa forma, acabam por agregar valor ao pescado, pois depois o processamento permite o consumo imediato, além de incrementar o valor de troca do pescado.

Além do beneficiamento inicial do pescado, às mulheres também compete, no mais das vezes, o reparo e a confecção de redes de pesca. As malhas, hoje tecidas em fios de nylon, são elaboradas de forma a prender o pescado dentro da rede, podendo, portanto, variar conforme a espécie de pescado a ser capturado. Esse trabalho é tradicionalmente do campo feminino na pesca - e tornaram-se famosas as mulheres "rendeiras". Tanto assim é que inclusive a localidade da Lagoa da Conceição, em Florianópolis, teve por nome de "Rendeiras" sua principal via de acesso ${ }^{35}$.

34 Entende-se aqui atividades vinculadas à empresa do turismo, tais como cozinheiras, camareiras, comerciárias e garçonetes. Dessa maneira, a comunidade local tornou-se mão de obra pouco especializada para o desenvolvimento da exploração turística das praias. Embora os níveis salariais não sejam atraentes, tais atividades suplantaram a realização da pesca.

35 As Rendeiras, patrimônio cultural local, são mulheres que ainda trabalham em pequenos "ateliêr", ao longo de toda a avenida central da região conhecida como Lagoa 
O Processo de Industrialização do Setor Pesqueiro e a Desestruturação da Pesca Artesanal no Brasil a partir do Código de Pesca de 1967

Todas as atividades desenvolvidas pelas mulheres agregam valor econômico, e, portanto, são relevantes fontes de sustento para suas famílias. Há o reconhecimento, nas localidades referidas, da importância do trabalho das mulheres, tanto por seus familiares como por parte das próprias mulheres. (BORGONHA; BORGONHA, 2008)

Além da importância imediata na agregação de valor econômico do trabalho realizado pela mulher, não se pode ignorar que essas mulheres são a base do sustento cultural da atividade pesqueira. Não só porque ensinam seus filhos e filhas a desenvolver a atividade pesqueira, preservando formas de trabalho tradicional, mas também porque lutam pela própria perpetuação da comunidade. Realizam-se como sujeitos políticos quando se envolvem na luta por melhores condições de vida e na resistência contra processos especulativos sobre as terras onde vivem. (MANESKI, 2000)

Apesar de seu importante papel, reconhecido por suas comunidades, as mulheres pescadoras tem seu trabalho como extensão natural dos afazeres domésticos. Isso porque não é considerada profissional autônoma da pesca artesanal. Muitas delas não detêm qualquer registro do desenvolvimento de suas atividades. Por isso, são ignoradas pela previdência social e mesmo pela legislação de acidentes de trabalho. Sem acesso, muitas vezes, a serviços como creches ou a benefícios trabalhistas como licença maternidade, essas mulheres não tem qualquer estímulo a permanecerem na atividade pesqueira, preferindo atividades como empregadas domésticas e faxineiras. (CABRAL; STADTLER; TAVARES, 2009)

O completo esquecimento do trabalho da mulher pescadora leva à desagregação de toda a pesca artesanal. Ora, a relação da mulher com o ambiente da pesca artesanal é justamente repassar os conhecimentos tradicionais às novas gerações. Com o desaparecimento da figura da mulher

da Conceição, no município de Florianópolis. Essas mulheres são referências turísticas da região - muitos adquirem peças confeccionadas ainda de maneira tradicional. A produção das rendeiras está voltada para a produção de trabalhos manuais artísticos voltados ao vestuário e peças decorativas, por meio de finas linhas e do bilro. Antes da valorização turística e cultural da atividade, era comum essas mulheres, a fim de garantirem os rendimentos familiares, trabalharem com a confecção e reparo de redes utilizadas para a pesca. (KUHNEN, 2002) 
pescadora, o que se perde é mais que força de trabalho: perde-se a identidade cultural das comunidades pesqueiras com a consequente a dissolução das próprias comunidades.

Essa composição social é bastante característica de comunidades exclusivamente pesqueiras. Ou seja, de grupos humanos que sobrevivem unicamente da pesca, que angariam por meio da atividade pesqueira além de recursos imediatos para consumo, recursos econômicos para a aquisição de outros bens. Há outras comunidades, entretanto, que subsistem parcialmente da pesca artesanal, dedicando outra parte do tempo a atividades agropastoris e turísticas. Para essas duas modalidades, é comum a organização das unidades de produção pelo próprio grupo familiar (que pode inclusive englobar a vizinhança). A continuidade desse modo de produção depende da coesão dos grupos humanos. (DIEGUES, 1983)

Em comunidades exclusivamente pesqueiras mercantis, é comum uma incipiente divisão do trabalho também entre os homens, visando maior sucesso na captura do pescado. Isso porque a única forma de aquisição dos bens de consumo é por meio do comércio do pescado, necessitando, portanto de maior volume de produção. Essas comunidades são caracterizadas pelo desligamento do homem em relação ao trabalho agrícola. Comumente, tal afastamento da lida agrícola ocorre em virtude da alienação das terras produtivas, em virtude da especulação imobiliária que ocorre nas localidades litorâneas brasileiras.

Ocorre que a sobrevivência dessas comunidades, exclusivamente ou não, pesqueiras, é ameaçada pela influência da industrialização do setor pesqueiro. A industrialização do setor pesqueiro no Brasil desconsiderou a importância da atividade comunitária pesqueira. Foi notável que o Código de Pesca de 1967 estimulou a indústria da pesca, com grande aparato tecnológico, mas silenciou em relação à pesca artesanal.

Dessa política pública, resultaram dois efeitos, que culminaram com a dissolução de grande parte do modo de pesca artesanal. O primeiro deles, houve o esgotamento dos cardumes pesqueiros em torno das áreas costeiras. Isso porque o pequeno pescado serve de isca nas grandes embarcações, além de as embarcações industriais realizarem a pesca sem qualquer intuito de preservação. O outro efeito foi a pauperização da co- 
O Processo de Industrialização do Setor Pesqueiro e a Desestruturação da Pesca Artesanal no Brasil a partir do Código de Pesca de 1967

munidade pesqueira, que, impulsionada pela exploração imobiliária, acabou por alienar seus imóveis.

O destino desses pescadores passou a ser os grandes centros urbanos, para a realização de outras tarefas, como na construção civil, ou ainda servir de mão de obra para a indústria pesqueira. Entrepostos pesqueiros industriais como os de Santos e os do Rio de Janeiro atraíram boa parte dos pescadores, que se transformaram de pequenos proprietários em trabalhadores assalariados na indústria pesqueira.

Com isso, mais que um modo de produção, o que desaparece é todo um modo de vida comunitário, tradicionalmente elaborado e vivido. Assim, a cultura das comunidades pesqueiras artesanais se desfez, englobando não apenas a forma de angariar os recursos pesqueiros, mas todo o cotidiano dos grupos humanos.

Nesse aspecto, são parcialmente efetivas as políticas estatais creditícias de estímulo à atividade pesqueira artesanal. Para a manutenção de comunidades pesqueiras, mais do que crédito, são necessárias políticas para a reprodução social do conhecimento essencial à atividade pesqueira. Isso porque a tendência à industrialização afastou grande parte do contingente populacional que encontrava sustento pela pesca artesanal. Com isso, o conhecimento necessário para a pesca artesanal desapareceu em certas comunidades. Essa forma de conhecimento é adquirida pela relação das gerações anteriores com o meio ambiente. Com o afastamento em relação ao setor pesqueiro, ocorre o distanciamento das gerações em relação à atividade pesqueira, com a opção dos subempregos nas cidades.

Assim, o que se antevê é justamente a falência da pesca artesanal, apesar dos incentivos econômicos através de empréstimos a baixas taxas de juros por parte do governo federal.

O desaparecimento das comunidades pesqueiras acarreta não apenas a migração de grande contingente para as cidades, a ocuparem subempregos. Tem também por consequência o afastamento do pescador do mar. Com isso, o ganho é necessariamente de ramos da especulação imobiliária, que pretende a aquisição das terras próximas à orla para a construção de grandes empreendimentos. 
Olga Maria Boschi Aguiar de Oliveira e Vera Lúcia da Silva

\section{Preponderância do Industrialismo no Setor Pesqueiro Brasi- leiro - Código de Pesca de 1967 e Lei de Pesca de 2009}

As normas que regulamentaram o setor pesqueiro no Brasil, de 1967 e 2009, procuraram dinamizar a atividade da pesca. Para tanto, a estratégia do Código de Pesca de 1967 foi a concessão de estímulos ao desenvolvimento da pesca industrial. Em 2009, a tentativa foi, aparentemente, da pesca artesanal.

A intervenção do Estado brasileiro no campo econômico, na década de 1960, foi intensa. O discurso desenvolvimentista legitimava o dirigismo estatal na economia (FURTADO, 1981). O acervo de normas jurídicas produzidas durante o período de 1960-1980 permite vislumbrar com clareza esta hipótese.

O ideário predominante à época era que o desenvolvimento de um país estava atrelado ao padrão produtivo. O que significa que um país desenvolvido se diferencia de um país subdesenvolvido pelo setor produtivo. Sob essa perspectiva, desenvolvimento e subdesenvolvimento seriam fases de evolução de um país, mensurável a partir da produção nacional. Conforme as condições de produção fossem eficientes, haveria o desenvolvimento econômico-social consequente. (FURTADO, 1981)

Se o padrão produtivo pode revelar o estágio no processo de desenvolvimento em que um país se encontra, então é preciso qualificar qual padrão produtivo está próximo ao desenvolvimento. Esse padrão certamente reflete a realidade de países ditos desenvolvidos, entre os quais figurava, à década de 1960, os Estados Unidos da América.

Se os Estados Unidos representavam o modelo de nação desenvolvida, os padrões produtivos e sociais daquele país serviram de paradigma ao Brasil. Portanto era consenso que a produção nacional, seja de produtos agrícolas, seja de produtos industriais, necessitava de profundas mudanças.

Dentre essas mudanças, alguns economistas, como Celso Furtado (1981), postulavam a alteração nos padrões produtivos do setor primário. Se o Brasil ainda era um país agrícola, era preciso promover a moderni- 
O Processo de Industrialização do Setor Pesqueiro e a Desestruturação da Pesca Artesanal no Brasil a partir do Código de Pesca de 1967

zação do setor. Para tanto, era necessário reorganizar a estrutura fundiária do país.

O Brasil à época era caracterizado pela vasta propriedade rural, muitas vezes improdutiva. Isso porque a concessão das terras realizada desde o período colonial não correspondeu a um modelo de distribuição, mas sim facilitou a concentração da propriedade. Para Furtado (1981), as estruturas tradicionais de produção impediam o desenvolvimento do Brasil.

Por outro lado, a postura de alguns intelectuais, assim como do governo militar instaurado em 1964 era de que o problema do subdesenvolvimento brasileiro era a falta de modernização. Tal ideia era pautada na teoria clássica de desenvolvimento. Para superar essa fase em rumo ao desenvolvimento nacional, fazia-se necessário modernizar os modos de produção, oferecendo eficiência e maior aproveitamento dos recursos naturais e humanos. (CUNHA, 2011)

Dessa forma, a política adotada para o desenvolvimento nacional foi fundamentada na industrialização dos setores produtivos (com a mecanização do campo e, consequentemente, da pesca), o recrutamento de mão de obra especializada, o controle das atividades sindicais e massivos investimentos estatais em indústrias e no setor econômico. (FURTADO, 1981)

O discurso de identidade entre industrialização e desenvolvimento nacional preponderou nos governos militares. Tanto assim foi que as medidas para a modernização do país foram políticas estatais de incentivos à afirmação da indústria nacional. A incipiente indústria nacional, entretanto, não contava com aparato tecnológico suficiente para sua modernização. Por esse motivo, o Brasil industrializou-se como economia dependente, a partir da aquisição de insumos e maquinários de países desenvolvidos. Assim foi que grande parte do maquinário industrial para compor as indústrias nacionais provinham de países desenvolvidos, especialmente dos Estados Unidos. Esse maquinário quando instalado no Brasil já era obsoleto. E por isso a industrialização do Brasil nem mesmo serviu à transformação dele em um país moderno no sentido tecnológico. (FURTADO, 1981) 
Para a importação do maquinário industrial, eram necessários vultosos investimentos. Ocorre que os setores que detinham o capital acumulado para impulsionar a industrialização eram justamente formados pelas tradicionais elites agrárias, cujo capital foi formado a partir da exploração da arcaica estrutura fundiária do Brasil (latifúndio, mão de obra escrava, colonato e produção para mercado externo) (FURTADO, 1977). Dessa maneira, a industrialização nacional dependeu diretamente de estruturas sociais antiquadas e não voltadas à modernização.

E, para completar o quadro de industrialização não modernizante do Brasil, os governos militares durante a década de 1960 promoveram massivos investimentos para o desenvolvimento industrial. Com isso, a indústria nacional é reforçada a partir de padrões estabelecidos pela classe política. Ocorre que a classe política dos militares era aliada das antigas elites agrárias. Assim, divisas nacionais foram utilizadas para a constituição e desenvolvimento de indústrias nacionais de base (siderurgia, metalurgia), além dos investimentos em forma de isenção de impostos para as grandes empresas, nacionais ou estrangeiras. (FURTADO, 1981)

Tal modelo de atuação estatal consolidou um modelo industrial tecnologicamente dependente dos países desenvolvidos e economicamente vinculados às elites agrárias, urbanas e ao capital estrangeiro. Para estimular a industrialização nesses moldes, os governos militares lançaram mão do aparato estatal para a promoção de infraestrutura necessária às indústrias (portos, estradas e indústrias de base). Grandes investimentos foram realizados pelo Estado, sem contar com arrecadação suficiente, pois às empresas e indústrias que no Brasil se instalavam eram concedidas isenções tributárias, como forma de estímulo. (CUNHA, 2011)

Os resultados desse processo de industrialização conduzido pelo Estado foram o endividamento do Brasil frente às instituições internacionais de crédito e a consolidação de uma indústria de tecnologia obsoleta. No aspecto das relações sociais, foram mantidas as mesmas elites do poder (agrárias e urbanas), com as garantias institucionais aos trabalhadores suprimidas. (FURTADO, 1981)

A partir dessas considerações gerais, é possível compreender a construção de estatutos jurídicos como o Código de Pesca de 1967. No 
O Processo de Industrialização do Setor Pesqueiro e a Desestruturação da Pesca Artesanal no Brasil a partir do Código de Pesca de 1967

auge dos governos militares, o setor pesqueiro foi regulamentado, imbuído de toda a ideologia dominante no período - desenvolvimento, formação da indústria nacional, substituição de importações e estímulo à concentração de capitais.

Mecanismos como a isenção de Imposto de Renda (IR), entre 1967 e 1989 sobre os resultados financeiros de pessoas jurídicas ${ }^{36}$, e dos Impostos de Importação (II) e sobre Produtos Industrializados (IPI) para a importação de maquinário e petrechos pesqueiros $^{37}$ foram previstos no Código de Pesca. Tais isenções representaram intenso investimento estatal no concurso para a consolidação do modelo industrial na pesca.

Esse referido modelo, baseado na produção industrial não modernizante, estrutura-se na concentração de capitais. O que ocorre é o desenfreado incremento da pesca industrial. Com isso, os recursos pesqueiros são largamente explorados. Dessa exploração, resulta a sensível diminuição

36 Dispositivos do Código de Pesca, de 1967 (Decreto-Lei n. 221/1967). Vale a pena a conferência do texto legal, que literalmente estabelece as isenções e suas condições. É importante destacar que os benefícios são somente concedidos a empresas (pessoas jurídicas) que estivessem vinculadas à Superintendência de Desenvolvimento da Pesca (SUDEPE), órgão governamental de apoio às políticas industriais durante os governos militares no Brasil. Destaque-se que o benefício previsto no artigo 80 foi prorrogado por uma série de leis posteriores, até o ano de 1989. Foram, portanto, 22 anos de isenção de Imposto de Renda para as indústrias da pesca.

Art. 80 - Na forma da legislação fiscal aplicável, as pessoas jurídicas que exerçam atividades pesqueiras, gozarão até o exercício financeiro de 1972, de isenção do Imposto de Renda e quaisquer adicionais a que estiverem sujeitas, com relação aos resultados financeiros obtidos de empreendimentos econômicos, cujos planos tenham sido aprovados pela SUDEPE.

Artigo 81 Todas as pessoas jurídicas registradas no país poderão deduzir no imposto de renda e seus adicionais, até o exercício financeiro de 1972, o máximo de $25 \%$ (vinte e cinco por cento) do valor, do imposto devido para inversão em projetos de atividades pesqueiras que a SUDEPE declare, para fins expressos neste artigo, de interesse para o desenvolvimento da pesca no país.

37 Artigo 73. É concedida, até o exercício de 1972, isenção do imposto de importação, do imposto de produtos industrializados, bem como de taxas aduaneiras e quaisquer outras federais para a importação de embarcações de pesca, equipamentos, máquinas, aparelhos, instrumentos e respectivos sobressalentes, ferramentas dispositivos e petrechos para a pesca, quando importados por pessoas jurídicas de acordo com projetos que forem aprovados pela SUDEPE na forma das disposições regulamentares. 
dos cardumes costeiros (DIEGUES, 1983). A redução dos cardumes costeiros consequentemente afeta a vida das comunidades pesqueiras artesanais. E, por outro lado, o incentivo físcal dirigido às indústrias acarretou a queda de valor de troca do pescado. Com isso, o pequeno pescador e as comunidades pesqueiras são forçadas a abandonar a sua atividade.

A consolidação do modelo de pesca industrial por grandes empresas e a falência do modo tradicional e artesanal de produção é perceptível pelos dados oficiais da SUDEPE ${ }^{38}$. Em 1960, enquanto a pesca artesanal no Brasil produzia $83,6 \%$ do pescado nacional, a pesca industrial era responsável por 16,4\%. Já no ano de 1970, após aproximadamente três anos de vigência do Código de Pesca, a pesca artesanal foi responsável por $53,4 \%$ da produção pesqueira, contra $46,6 \%$ da pesca industrial. Durante os quatro primeiros anos da década de 1970, a SUDEPE distribuiu, em incentivos fiscais, mais de um bilhão de cruzeiros entre empresas de grande porte $^{39}$.

As recentes políticas para o setor pesqueiro, estabelecidas pela Lei n. 11.959/2009, estimulam a inserção de elementos como divisão do trabalho e do trabalho assalariado. Isso porque reconhece a condição de "pescador não embarcado", sem esclarecer se este pescador pode ser somente o proprietário da embarcação, sem trabalhar na atividade pesqueira. A falta de clareza sobre o desenvolvimento prático da atividade pesqueira artesanal acarreta essa confusão no conceito de pescador, base da definição de pesca artesanal.

Além disso, a concessão do crédito rural faz com que as poucas comunidades pesqueiras artesanais resistentes sejam convertidas em pequenas unidades produtivas de grandes indústrias, repassando-lhes diretamente toda a produção pesqueira. Isso porque não há qualquer tutela das pequenas comunidades pesqueiras (e poucas existentes) contra a pressão exercida por grandes empresas consolidadas e monopolizadoras do mer-

38 SUDEPE - Superintendência de Desenvolvimento da Pesca, criada em 1967, pelo Código de Pesca, no intuito de facilitar as relações institucionais entre governo e grandes empresas pesqueiras. Facilitava a concessão das isenções tributárias previstas.

39 Obtidos através do sítio do Ministério de Relações Exteriores. Disponível em: $<$ http:// www2.mre.gov.br/dai/b_rfa_287_356.htm>. Acesso em: 31 jul. 2011. 
O Processo de Industrialização do Setor Pesqueiro e a Desestruturação da Pesca Artesanal no Brasil a partir do Código de Pesca de 1967

cado. Dessa maneira, em nada a Lei de Pesca de 2009 contribui para o resgate ou o reconhecimento da pesca artesanal como forma de trabalho a ser valorizada e garantida.

\section{Conclusões}

A regulação brasileira do setor pesqueiro foi composta por duas normas: o Código de Pesca de 1967 e a Lei de Pesca de 2009. Analisando o texto legal de ambas, ficou evidente a atuação do Estado brasileiro, sob governos autoritários ou democráticos uma mesma tendência - a industrialização não modernizante do setor. Com esse objetivo, o Estado assume um papel intervencionista, em prol do modo de produção industrial. A consequência é a dissolução de outras formas produtivas não industriais, como a pesca artesanal.

Inicialmente, o Código de Pesca de 1967, estabeleceu privilégios às indústrias pesqueiras com isenção de impostos. Não houve, por este Código, qualquer diretriz sobre pesca artesanal, e nem mesmo sua definição jurídica. Tal definição foi estabelecida somente em 2003, por meio da legislação sobre seguro-desemprego para pescadores, que incluiu como beneficiários os pescadores artesanais.

Em 2009, foi revogado o Código de Pesca pela Lei de Pesca (Lei n.11.959/2009). Essa nova lei trouxe a definição de pesca artesanal em seu texto, bem como uma política específica de estímulo a essa modalidade produtiva - a concessão de crédito por juros abaixo das tabelas de mercado.

Apesar da iniciativa governamental, o estímulo concedido não é eficiente para a rearticulação da pesca artesanal. Aliás, continua contribuindo para a industrialização da pesca. Isso por dois motivos. O primeiro - a concessão de crédito visa estimular a divisão do trabalho entre patrões de pesca e pescadores, não estimulando o modo de produção comunitário. E como segundo motivo aponta-se o fato de que as comunidades pesqueiras já foram desarticuladas desde a década de 1960. Com isso, alienaram suas propriedades nos litorais e nas áreas ribeirinhas, que, somado com a especulação imobiliária de muitas dessas regiões, impede o restabelecimento 
Olga Maria Boschi Aguiar de Oliveira e Vera Lúcia da Silva

dessas comunidades. Ao lado disso, a falta de estímulo e reconhecimento jurídico aos profissionais da pesca (especialmente as mulheres) acarreta certamente, o esvaziamento do setor.

Diante desses fatos, a conclusão é a de que o Estado continua intervindo no setor produtivo pesqueiro sob a égide do desenvolvimentismo industrialista. A ruptura de modos de produção comunitários artesanais não é uma consequência relevante em termos institucionais, embora seja em níveis culturais e políticos.

\section{Referências}

BORGONHA, Mirtes Cristina; BORGONHA, Maíra. Mulherpescadora e mulher de pescador: a presença da mulher na pesca artesanal na Ilha de São Francisco do Sul, Santa Catarina. 2008. Disponível em: <http://www.fazendogenero8.ufsc.br/sts/ST64/BorgonhaBorgonha_64.pdf $>$. Acesso em: 17 jul. 2011.

CABRAL, Maria das Mercês C.; STADTLER, Hulda; TAVARES, Lyvia (2009). Mulheres pescadoras: gênero e identidade, saber e geração.

UFP: João Pessoa. Disponível em: <http://itaporanga.net/genero/gt5/7. pdf>. Acesso em: 17 jul. 2011.

CALIL, Léa Elisa S. Direito do Trabalho da mulher: a questão da igualdade jurídica ante a desigualdade fática. São Paulo: LTr, 2007.

CHAVES, Paulo de Tarso; ROBERT, Maurício de Castro. Embarcações, artes e procedimentos da pesca artesanal no litoral sul do Estado do Paraná, Brasil. Atlântica, Rio Grande, 2003.

CUNHA, André Moreira. A colonização e o desenvolvimento capitalista do Brasil. [2012]. Disponível em: <http://www.ufrgs.br/ decon/publionline/textosdidaticos/textodid14.pdf $>$. Acesso em: 31 ago. 2011.

DIEGUES, Antônio Carlo Sant'Ana. Pescadores, camponeses e trabalhadores do mar. São Paulo: Ática, 1983. 
O Processo de Industrialização do Setor Pesqueiro e a Desestruturação da Pesca Artesanal no Brasil a partir do Código de Pesca de 1967

FIGUEIREDO, Ana Cristina Almeida de O.; LEITÃO, Maria do Rosário de Fátima de Andrade. Gênero e extensão pesqueira no município de Itapissuma - PE. 2010. Disponível em: <http://www.ufrpe-posmex.org/ index.php?option $=$ com_docman\&task $=$ cat_view\&gid $=51 \&$ Itemid $=80>$. Acesso em: 31 ago. 2011.

FURTADO, Celso. Formação econômica do Brasil. 15. ed. São Paulo: Editora Nacional, 1977.

O mito do desenvolvimento econômico. 5. ed. Rio de Janeiro: Paz e Terra, 1981.

KUHNEN, Ariane. Lagoa da Conceição: meio ambiente e modos de vida em transformação. Florianópolis: Cidade Futura, 2002.

LOPES, Cristiane Maria S. Direito do trabalho da mulher: da proteção à promoção. Cadernos Pagu. Campinas/SP, v. 26. p. 405-430, 2006.

MANESKY, Maria Cristina. Da casa ao mar: papéis das mulheres na construção da pesca responsável. Revista Proposta, Rio de Janeiro, n. 84/85, Federação de Órgãos para Assistência Social e Educacional, 2000.

MARTINS, Sérgio Pinto. Direito do Trabalho. 14. ed. São Paulo: Atlas, 2001.

MELO, Maria de Fátima Massena de. (2008) Políticas públicas entre pescadoras artesanais: invisibilidade do trabalho produtivo e reprodutivo. Anais. VIII Congresso Fazendo Gênero. Universidade Federal de Santa Catarina, 2008. Disponível em: <http://www.fazendogenero8.ufsc.br/sts/ ST15/Maria_de_Fatima_Massena_de_Melo_15.pdf $>$. Acesso em: 6 jul. 2011.

PASQUOTTO, Vinicius Frizzo. (2005) Pesca artesanal no Rio Grande do Sul: os pescadores de São Lourenço do Sul e suas estratégias de reprodução social. Porto Alegre, Programa de Pós-Graduação em Desenvolvimento Rural da Faculdade de Ciências Econômicas da Universidade Federal do Rio Grande do Sul. 2005. Disponível em: $<$ http://www.lume.ufrgs.br/bitstream/handle/10183/7029/000538698. pdf?sequence=1>. Acesso em: 7 jul. 2011. 
Olga Maria Boschi Aguiar de Oliveira e Vera Lúcia da Silva

SEVERO, Christiane Marques. Pesca artesanal em Santa Catarina: evolução e diferenciação dos pescadores da Praia da Pinheira. Porto Alegre, 2008. Dissertação de Mestrado. Programa de Pós-Graduação em Desenvolvimento Rural da Faculdade de Ciências Econômicas da Universidade Federal do Rio Grande do Sul. Disponível em: <http:// www.lume.ufrgs.br/bitstream/handle/10183/15012/000674207. pdf?sequence $=1>$. Acesso em: 7 jul. 2011.

WEBER, Max. Economia e sociedade: fundamentos da sociologia compreensiva. 4. ed. Tradução de Regis Barbosa e Karen Elsabe Barbosa.

Brasília: UnB, 2009. 